Article

\title{
Ultrafine Particle Features Associated with Pro-Inflammatory and Oxidative Responses: Implications for Health Studies
}

\author{
Francesca Costabile $^{1, *(\mathbb{D})}$, Maurizio Gualtieri ${ }^{2} \mathbb{D}$, Carla Ancona ${ }^{3}$, Silvia Canepari ${ }^{4}(\mathbb{D})$ and \\ Stefano Decesari ${ }^{5}$ \\ 1 ISAC-CNR, via Fosso del Cavaliere, 00131 Rome, Italy \\ 2 ENEA, via Martiri di Monte Sole, 40129 Bologna, Italy; maurizio.gualtieri@enea.it \\ 3 Epidemiology Department Lazio Regional Health Authority, via C. Colombo, 00147 Roma, Italy; \\ c.ancona@deplazio.it \\ 4 Department of Chemistry, Sapienza University of Rome, P.le Aldo Moro, 5, 00185 Rome, Italy; \\ silvia.canepari@uniroma1.it \\ $5 \quad$ ISAC-CNR, via Gobetti, 40129 Bologna, Italy; s.decesari@isac.cnr.it \\ * Correspondence: f.costabile@isac.cnr.it; Tel.: +39-06-4548-8288
}

Received: 17 March 2020; Accepted: 17 April 2020; Published: 21 April 2020

\begin{abstract}
Suspected detrimental health effects associated with ultrafine particles (UFPs) are impressive. However, epidemiological evidence is still limited. This is potentially due to challenges related to UFP exposure assessment and the lack of consensus on a standard methodology for UFPs. It is imperative to focus future health studies on those UFP metrics more likely to represent health effects. This is the purpose of this paper, where we extend the results obtained during the CARE ("Carbonaceous Aerosol in Rome and Environs") experiment started in 2017 in Rome. The major purpose is to investigate features of airborne UFPs associated with pro-inflammatory and oxidative responses. Aerosol chemical, microphysical, and optical properties were measured, together with the oxidative potential, at temporal scales relevant for UFPs (minutes to hours). The biological responses were obtained using both in-vivo and in-vitro tests carried out directly under environmental conditions. Findings indicate that caution should be taken when assessing health-relevant exposure to UFPs through the conventional metrics like total particle number concentration and $\mathrm{PM}_{2.5}$ and Black Carbon (BC) mass concentration. Conversely, we recommend adding to these, a UFP source apportionment analysis and indicators for both ultrafine black carbon and the size of particles providing most of the total surface area to available toxic molecules.
\end{abstract}

Keywords: ultrafine particles; black carbon; combustion; pro-inflammatory responses; oxidative responses; health; air quality; oxidative potential; source apportionment; particulate matter

\section{Introduction}

Nearly half of all people in the world now live in cities, thus air quality is increasingly polluted. Urban air pollution associated with fine particulate matter (particles with aerodynamic diameter less than $2.5 \mu \mathrm{m}, \mathrm{PM}_{2.5}$ ) is considered the leading environmental health risk factor globally, causing several million deaths per year [1-4]. Although the EU Ambient Air Quality Directives [5] and the USA National Ambient Air Quality Standard (NAAQS) contain regulatory limits for PM 2.5 , the World Health Organisation highlighted that the low end of the range of concentrations at which health effects can occur is well below these limits (not greatly above $3-5 \mu \mathrm{g} \mathrm{m}^{-3}$ for $\mathrm{PM}_{2.5}$ ) [1,6]. It is unlikely that any future standard for $\mathrm{PM}_{2.5}$ will lead to complete protection. In the USA, there is strong agreement across studies that air pollution-related adverse health effects are still observable at low concentrations, even 
well below current standards [7]. In Europe, the EC has decided to revise the standards, although the choice of the best-suited indicator (or combination of indicators) to measure health risk from particulate matter is still to be made. Therefore, it is necessary to provide significant scientific evidence to guide the development of new recommendations, policies, and legislation, given that further improving air quality has the potential of benefiting public health. The $\mathrm{PM}_{0.1}$ (particles with aerodynamic diameter less than $100 \mathrm{~nm}$ ), particularly those derived from combustion, is at the centre of the scientific debate for potential detrimental effects on human health. Several studies refer to $\mathrm{PM}_{0.1}$ as ultrafine particles (UFPs), although some papers point at the importance of also including in UFPs particles up to $500 \mathrm{~nm}$ (the accumulation mode fraction), e.g., [8,9]. Research on UFPs is now devoted to understanding the factors triggering the suspected potential health effects. A number of challenges need to be solved, among which there is the need to converge toward a new methodology to assessing exposure to UFPs. The conventional paradigm for $\mathrm{PM}_{2.5}$ is based on daily mass concentration data at a few representative sites. Compared to $\mathrm{PM}_{2.5}$, UFPs show reduced spatiotemporal scales of variability (minutes and meters), the mass concentration poorly (or not) representing them, e.g., [10-15]. The measurement of UFPs thus requires data with a higher time resolution (less than $1 \mathrm{~h}$ ) taken at a larger number of sites, as well as new metrics. Rather than mass concentration, the total particle number concentration $\left(\mathrm{N}_{\text {tot }}\right)$ can reflect the contribution of UFPs and has hence been used by several studies, e.g., [16-18]. Particle surface area and particle length better correlate with the biological and toxicological activity of particles and have hence gained increasing interest, e.g., [18-23]. As the debate is still in progress, it is imperative to find a consensus on what the best-suited indicators are, how to measure them through a standard procedure, and accordingly push the development of regulations for UFPs.

Airborne UFPs are not a homogeneous substance but consist of a complex mixture of very different particle types. These are either formed in the atmosphere or emitted, mainly from combustion. Processing in the ambient air dramatically changes UFPs, the dynamics being governed by nucleation, coagulation, and condensation processes. Each of these processes results in different particle types, which are well represented by specific particle size ranges: less than $20-30 \mathrm{~nm}$ for the nucleation mode, 30-100 $\mathrm{nm}$ for the Aitken mode, and 100-700 $\mathrm{nm}$ for the accumulation mode. Whilst UFP size can be measured with state-of-the-art technology, the measurement of the chemistry of UFPs is still challenging. A variety of substances possibly present in UFPs are considered highly toxic, such as organic molecules (e.g., Polycyclic aromatic hydrocarbons, PAH), redox-active metals, elemental carbon (or black carbon, BC), soluble hydrocarbons, and secondary organic aerosol [12-15]. It is also challenging to measure the other features of UFPs, including physical state (solid, liquid, glassy), shape (from fractal-like to spherical), mixing state (from externally to internally mixed), surface area reactivity, and solubility (in water and/or lipid).

Health effects associated to UFPs, even adjusting for potential confounders, are impressive: mortality, lung cancer, cardiopulmonary toxicity, DNA damage, severe cognitive deficits, Alzheimer's and Parkinson's disease, suicide, and dementia, e.g., [1,24-27]. There are two main pathways of entry for airborne UFPs: the olfactory route and the secondary, systemic route $[27,28]$. Owing to their small size, UFPs contain a high surface area-to-mass ratio, giving them a high potential for translocation and interaction with tissues, resulting in oxidative stress and inflammation within extra-pulmonary organs [29]. The translocation of UFPs depends on several factors, including size and physical state. The smaller the size, the faster the translocation. Oberdoster et al. [28] estimated that the nasal deposition efficiency for UFPs below $5 \mathrm{~nm}$ in diameter is nearly $100 \%$, whereas the efficiency is close to $10 \%$ for particles larger than $30 \mathrm{~nm}$. Bové et al. [30] provided compelling evidence for the presence of $\mathrm{BC}$ particles originating from ambient air pollution in human placenta and suggested that the translocation of UFPs from the mother's lung to the circulation to the placenta might be a plausible potential mechanism explaining their findings. BC enriched in UFPs (also referred to as ultrafine BC, $\mathrm{uBC}$, and/or soot and representing, at least partly, solid particles) has been hypothesized to play an important role in neurodegenerative disorders [31]. Shang et al. [32] raised concerns about the effects of ambient $\mathrm{uBC}$ (sizes of approximately $30 \mathrm{~nm}$ ) on the risk of Alzheimer's disease. 
Despite toxicological findings, epidemiological evidence is limited and inconclusive. The last Health Effect Institute's review [33], recently updated [34], concluded that existing studies do provide evidence for short-term health effects linked to UFP exposure like pulmonary and systemic inflammation, autonomic tone, and blood pressure, which may be at least partly independent of the concomitant exposure of other pollutants, but not for the other effects suspected. The inconclusive results are (mainly) due to the paucity of data about UFPs caused by a lack of national or international regulations. Only a few dedicated measurement campaigns and pilot projects have been conducted to measure UFPs and assess their relationship with health outcomes. As these measurement campaigns are often based on daily data and are limited to one UFP metric (mostly $\mathrm{N}_{\text {tot }}$ ) and one city, the few existing epidemiological studies on effects of short-term exposure to UFPs from these sites may lack adequate statistical power [35-38]. The UFIREG study conducted in Central Europe [39] and the UF \& Health in Nordic and Mediterranean cities [40] found weak evidence of an association between UFP and daily mortality. The inconclusive results might be attributed to the different UFP origins of the cities involved in the studies, or even to the different origin of UFPs for different days in a city. Due to the difficulties in characterizing spatial contrasts in population exposures to UFPs over a long period of time only a handful of studies about the impact of long long-term exposure of UFPs have reported positive associations between UFPs and specific mortality and disease incidence [41-45]. The first (to our knowledge) epidemiological study having investigated multiple UFPs with integrated metrics $\left(\mathrm{N}_{\text {tot }}\right.$, and particle length and surface concentration) at hourly resolution showed health effects (non-fatal myocardial infarction) in a few hours (3-6 h), which "may" be independent of co-pollutant exposure [46].

In 2017 we launched the "Carbonaceous Aerosol in Rome and Environs" (CARE) experiment with the scope to explore associations between physicochemical properties of the carbonaceous aerosol and toxicological mechanisms linked to pro-inflammatory and oxidative biological responses [47-54]. The findings obtained during the CARE experiment point consistently at the importance of considering additional aerosol metrics upon which to base health studies. However, none of the previous papers addressed directly a specific question: in view of the CARE results, what are the PM metrics able to weigh the pro-inflammatory and oxidative responses observed? And this is the scope of this paper. What makes the current analysis distinct from what was presented in the earlier papers from the CARE experiment is precisely the attempt to address directly that specific question. We show limitations of both the mass-based regulatory standards for PM2.5 and the conventionally used metrics for UFPs (total particle number concentration and $\mathrm{BC}$ mass concentration) in indicating the pro-inflammatory and oxidative responses observed during the CARE experiment, and we propose alternative approaches. Notably, in doing so, we do not assume that there is (are) UFP metric(s) relevant for any and all health effects, chronic or acute, respiratory or cardiovascular or neurological. Conversely, we aim at identifying metric(s) that can be considered as predictor(s) only for the pro-inflammatory and oxidative responses observed during the CARE experiment. Although it is clearly limited, the approach relies on the oxidative stress paradigm, a well-recognized and accepted hypothesis for several air pollution-related health diseases.

\section{Experimental Design}

The CARE experiment was carried out at a site representative of the urban background in the city centre of Rome (Italy), from 27 January to 28 February 2017. The experimental design is discussed in previous publications [47-54] and here outlined for the sake of clarity: aerosol instrumentation, protocols and methodologies in Section 2.1; oxidative potential of particulate matter in Section 2.2; toxicological endpoints in Section 2.3; aerosol source apportionment in Section 2.4; oxidative responses in Section 2.5. The different data obtained with the different techniques were merged into different datasets. Time resolutions varied from $5 \mathrm{~min}$ (size distribution and black carbon) to $1 \mathrm{~h}$ (non-refractory $\mathrm{PM}_{1}$ chemical components) to $2 \mathrm{~h}$ (oxidative potential) to 12/24 h (biological responses). Accordingly, the length of each dataset depends on this time resolution. 


\subsection{Aerosol Characterisation}

Aerosol chemical, microphysical, and optical properties were measured using different techniques, under dry conditions ( $\mathrm{RH}<30 \%$ ), with the highest time resolution available (from seconds to $1 \mathrm{~h}$ to $24 \mathrm{~h}$ ). We used a $\mathrm{PM}_{10}$ sampling head for microphysical and $\mathrm{PM}_{1}$ for chemical data. Major non-refractory $\mathrm{PM}_{1}$ chemical components, namely organic aerosol, nitrate, sulphate, ammonium, and chloride, were measured with a 30-min time resolution using an Aerodyne Aerosol Chemical Speciation Monitor (ACSM). The BC mass concentration was measured with 1-min time resolution through an Aethalometer (model A33, Magee Scientific, AE33) and a Multi Angle Absorption Photometer (MAAP, Thermo Scientific, Waltham, MA, USA). Continuous particle number size distributions (PNSDs) from 0.008 to $14 \mu \mathrm{m}$ (electrical mobility diameter), with a 5 -min time resolution, were measured by combining a Mobility Particle Size Spectrometer (TROPOS SMPS) equipped with a butanol-based condensation particle counter (CPC, TSI model 3772) and a commercial aerodynamic particle sizer (APS, TSI). Particles from 8 to $800 \mathrm{~nm}$ of electrical mobility diameter $(\mathrm{dm})$ were sized and counted using the SMPS; particles from 0.5 to $20 \mu \mathrm{m}$ of aerodynamic diameter $\left(\mathrm{d}_{\mathrm{a}}\right)$ were sized and counted using the APS. SMPS data were corrected for penetration errors through the sampling line (TROPOS-made software, Leipzig, Germany), penetration efficiency due to diffusion losses being higher than $98.92 \%$ for particles bigger than $15 \mathrm{~nm}$.

The dry 5-minute continuous PNSD from 0.008 to $14 \mu \mathrm{m}$ of electrical mobility diameter was obtained by merging data from two different instruments: a Mobility Particle Size Spectrometer (SMPS, TROPOS, Leipzig, Germany) equipped with a butanol-based condensation particle counter (CPC, TSI model 3772) and a commercial aerodynamic particle sizer (APS, TSI). The fitting procedure and methodology used to calculate the following parameters has been already described $[47,52,55]$. The median diameter $\left(D_{\text {med }}\right.$ ) of the entire (from 0.008 to $20 \mu \mathrm{m}$ ) particle surface size distribution (PSSD) was calculated from the PNSD. The $D_{\text {med }}$ is the electrical mobility diameter where $50 \%$ of the PSSD is lower than $D_{\text {med }}$. The $D_{\text {med }}$ is intended to provide information on the particle size range providing most of the surface area. $\mathrm{PM}_{2.5}$ and $\mathrm{PM}_{1}$ data with 5-min time resolution were reconstructed from the PNSD. A size dependent effective particle density was used. PM2.5 data were validated against the daily $\mathrm{PM}_{2.5}$ data measured from the local environmental agency (ARPA Lazio). $\mathrm{PM}_{1}$ data were validated against the $1 \mathrm{~h}$ data obtained merging the $\mathrm{BC}$ and NR-PM $\mathrm{PM}_{1}$ mass concentration.

\subsection{Oxidative Potential of the Particulate Matter}

The oxidative potential (OP) of $\mathrm{PM}_{2.5}$ was obtained in a cell free system as a measure of the capacity of $\mathrm{PM}_{2.5}$ to oxidize target molecules. The methodology is described in detail in previous publications $[47,56,57]$. Briefly, OP was determined using $2^{\prime} 7^{\prime}$-dichlorofluorescein (OPDCFH) assay, the non-fluorescent DCFH being oxidized to the fluorescent dichlorofluorescein (DCFH) in the presence of horseradish peroxidase (HRP). A particle-into-liquid sampler (PILS, ADI 2081, Metrohm AG, Herisau, Switzerland) was used to collect the aerosol. The output flow $(0.6 \mathrm{~mL} / \mathrm{min})$ was recovered in a vial using an automatic collector (SPS-5 Auto sampler, Varian, Palo Alto, CA, USA). The sampling line was equipped with a PM2.5 head and with a denuder line to exclude acid and basic gases from the sampling. Worthy of note is that, based on this methodology, the $\mathrm{OP}^{\mathrm{DCFH}}$ data refer to the water-soluble PM2.5 plus the suspended particle fraction passing through a $0.45 \mu \mathrm{m}$ filter, which includes insoluble non agglomerated UFPs. This $\mathrm{OP}^{\mathrm{DCFH}}$ might be considered as a proxy of the ability of the above-mentioned fraction of PM2.5 to generate reactive oxygen species (ROS, or free radicals). Different assays refer to different target molecules and are expected to lead to different OP values. The DCFH assay was formerly developed for the in-vitro determination of ROS in biological cells, and only recently adapted and applied as an acellular method as done in this work $[47,56,57]$. 


\subsection{Toxicological Endpoints}

Toxicological endpoints were obtained by both in-vitro and in-vivo analysis. For the in-vitro tests, cultured bronchial cells at the air liquid interface (ALI) were directly exposed, for the first time, to the atmospheric aerosol [48].the equipment used to measure toxicological endpoints at the ALI was installed at the same aerosol measurement site under environmental conditions (i.e., not dry). BEAS-2B cells, representative of bronchial epithelium, were cultured at the ALI on collagen coated inserts and $24 \mathrm{~h}$ before exposure they were differentiated by removing the culture medium on the apical section of the insert. The inserts were transferred to the CULTEX RFS Compact module, and then exposed directly at the atmospheric aerosol for $24 \mathrm{~h}$. Differential expression of genes related to inflammatory (IL-6), antioxidant (HO-1 and NQO1) and xenobiotic (Cyp1A1, AhR) responses were evaluated, as described in detail by Gualtieri et al. [48]. These genes were considered as representative of the main toxicological pathways activated in lung epithelium in-vitro models after exposure to PM, and they were possibly related to the mode of action of PM in relation to significant respiratory health outcomes $[48,50]$.

For the in-vivo tests, three nucleic acid oxidation biomarkers were determined in human urine: 8-Oxo-7,8-dihydro-2'-deoxyguanosine (8-oxodGuo) as a biomarker of the oxidative damage to DNA, 8-Oxo-7,8-dihydroguanosine (8-oxoGuo) as a biomarker of the oxidative damage to RNA, and 8-Oxo-7,8dihydroguanine (8-oxoGua) as a biomarker from both, but predominantly from DNA. The protocol is described in detail in previous publications [50,51]. It was intended to allow for the collection of an elevated number of samples ( 2 samples every $12 \mathrm{~h}$ ) for several consecutive days during a relatively short period (1 month) from 2 subjects (a man and a woman, aged 25 and 40, respectively) whose exposure conditions were representative of the atmospheric aerosol during the CARE experiment, in comparison to more than 200 subjects whose exposure varied from work environments to general population [51].

\subsection{Aerosol Source Apportionment}

Aerosol sources during the CARE experiment were apportioned to both advection-dominated and local contributions, on the basis of four different source apportionment analyses described in detail in previous publications $[47,50,53,58]$ and here summarised.

Firstly, an organic aerosol (OA) source apportionment was performed through an internal positive matrix factorization (PMF-ME2) procedure (SoFi) allowing the identification of emissions sources from the matrices of $\mathrm{OA} \mathrm{m} / \mathrm{z}$ measured by the aerosol mass spectrometer [47]. Three OA sources were recognized: vehicular traffic emission (hydrocarbon-like OA, HOA), biomass burning emission (BBOA), and oxygenated secondary aerosol (OOA).Findings from this PMF analysis of the OA were then coupled to a statistical analysis (principal component analysis, PCA)of the particle number size distributions (PNSD) with the aim to apportion combustion aerosol sources for UFPs [50]. Three principal components were extracted; the scores of these PCs are used in this paper. Two of these were combustion-derived aerosol types, i.e., UFPs deriving from fresh vehicular emissions (fossil fuel UFPs) and biomass burning. A component was also apportioned to dust. The physicochemical properties (PNSD and $\mathrm{PM}_{1}$ major chemical components) observed for the two combustion-derived aerosols are summarized in Figure S1. The fossil fuel UFPs were associated with the $\mathrm{PM}_{1}$ mass fraction of the HOA $\left(f_{\mathrm{HOA}}\right)$ enriched in $\mathrm{BC}$ (mass fraction of $\mathrm{BC}$ on average $20 \%$ ), the size distribution being mono-modal and peaking from 10 to $20 \mathrm{~nm}$. The biomass burning aerosol consisted of particles mainly in the accumulation mode size range enriched in $\mathrm{OA}$ and were associated with the BBOA component of the PMF.

An optical aerosol classification was performed to exploit multi-wavelength 1-h optical properties, validated through chemical composition and size distribution data [53]. Six different aerosol contributions were apportioned: three advection-dominated aerosol types (Saharan desert dust, sea salt, and an aged and polluted marine aerosol) and three local-source dominated aerosol types (biomass burning from a fire episode, traffic emissions, and biomass burning for residential heating). Further knowledge was gained on the source contribution to aerosol optical absorption properties and 
organics by applying an original approach based on receptor modelling coupling optical and chemical variables [58]. It was finally possible to identify nine components: biomass burning, nitrate and aged aerosol, traffic exhaust, sulphate, mineral dust, marine aerosol, traffic non-exhaust, local source, and polluted marine aerosol.

In this work, we focus on the local combustion aerosol dominated periods, when the toxicological endpoints were measured and combustion-related UFP contribution was dominant.

\subsection{Pro-Inflammatory and Oxidative Responses}

The biological responses obtained from in-vitro and in-vivo tests were compared against each other [50]. During the in-vitro tests, significant association of antioxidant genes was observed with secondary and aged aerosol, while cytochrome activation was observed with primary and PAHs-enriched UFPs [48]. During the in-vivo tests, a product of guanine oxidation related to RNA oxidation (8-oxoGuo) was suggested to be a suitable oxidative biological marker [51]. These independent biological measures were found to be consistent with each other and with the cell free OP ${ }^{\mathrm{DHCF}}$, their relations depending on combustion-derived UFPs [50]. Accordingly, in this paper we use the OPDHCF as an aggregate indicator of the biological responses. What makes the use of the 2-h OPDHCF values as compared to the 12/24-h biological endpoints advantageous is the number of data-points: the dataset length increases to 84 points. In addition, to get rid of the mass concentration influence, we use in the present paper the mass-normalised $\mathrm{OP}^{\mathrm{DHCF}}\left(\mathrm{OP}{ }^{\mathrm{DHCF}} / \mathrm{PM}_{2.5}\right)$. The $\mathrm{OP}^{\mathrm{DHCF}}$ data depend on both the intrinsic $\mathrm{OP}^{\mathrm{DHCF}}$ and the $\mathrm{PM}_{2.5}$ mass concentration, the latter being influenced by both aerosol particle size and mass concentration. Conversely, the mass-normalised OP weighs the intrinsic $\mathrm{OP}^{\mathrm{DHCF}}$ of each aerosol type, regardless of their different mass concentration and size.

\section{Results}

In this section, we analyse how the commonly used aerosol metrics for fine and ultrafine particles weigh the biological responses observed during the CARE experiment under conditions dominated by combustion aerosols (biomass burning and fossil fuel UFPs). The aerosol metrics analysed are the $\mathrm{PM}_{2.5}$ and $\mathrm{PM}_{1}$ mass concentration, $\mathrm{BC}$ mass concentration, and total particle number concentration, as well as the $\mathrm{BC}$-to- $\mathrm{PM}_{1}$ mass fraction $\left(\mathrm{f}_{\mathrm{BC}}\right)$ and median particle diameter of the surface-area size distribution $\left(D_{\text {med }}\right)$. First, we show the relationships between the combustion derived $\mathrm{PM}_{1}$ aerosols and the oxidative responses (Figure 1). Then, we show the relations between the combustion derived $\mathrm{PM}_{1}$ aerosols and the aerosol metrics (Figure 2). Finally, we show the relationships between the aerosol metrics and the oxidative responses (Figure 3).

Figure 1 shows the principal component scores (x-axis) apportioned to biomass burning (panels a-b) and fossil fuel UFPs (panels c-d). These are plotted against the PM2.5 oxidative potential (both OPDHCF and mass-normalised $\mathrm{OP}{ }^{\mathrm{DHCF}}$ ). The relations indicate increasing oxidative responses with increasing fossil fuel UFPs and decreasing biomass burning (Figure 1). The relation between both the combustion aerosols and the mass-normalised $\mathrm{OP}^{\mathrm{DHCF}}$ is monotonic, but not linear (the Spearman correlation, a benchmark for monotonic relationships, is greater than the Pearson correlation, a benchmark for linear relationships, Figure $1 b, d)$. Note that the relation between biomass burning and $\mathrm{OP}^{\mathrm{DHCF}}$ is not statistically significant $(p=0.845$, Figure $1 \mathrm{a})$, whilst this is not the case in the remaining three panels (Figure 1b-d).

Figure 2 shows that the fossil fuel UFP score was high with lower $\mathrm{D}_{\text {med }}$, contrarily to the biomass burning aerosol (panels $\mathrm{f}, \mathrm{n}$ ). Conversely, the score of the biomass burning aerosol increased with increasing the mass concentration of $\mathrm{PM}_{2.5}, \mathrm{PM}_{1}$, and $\mathrm{BC}$ (panels g-i), contrarily to the fossil fuel UFPs (Figure 2a-c). 

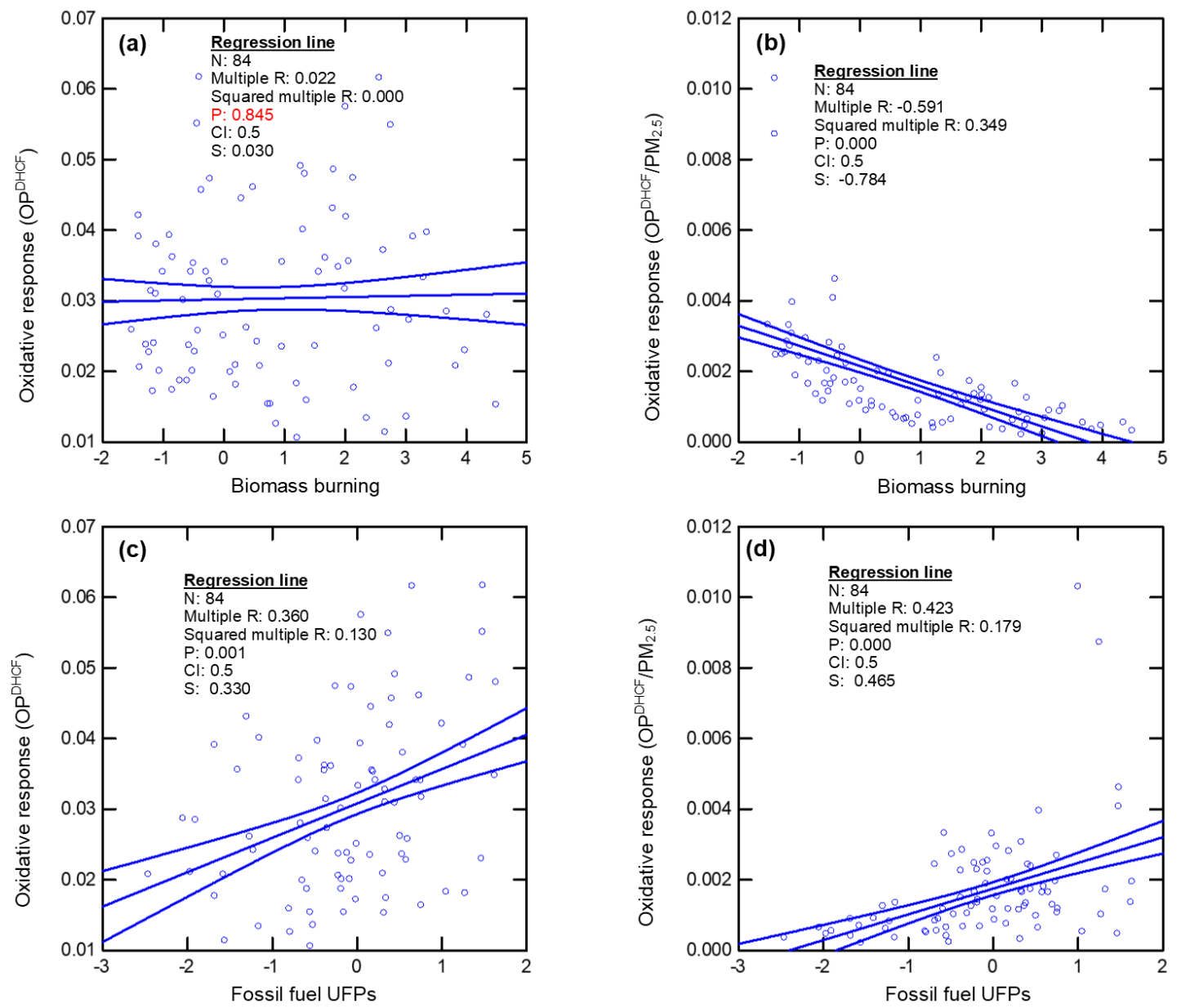

Figure 1. Linear regression of the oxidative response (both as oxidative potential, $\mathrm{OP}^{\mathrm{DHCF}}$, panels (a,c), and mass-normalised-OP ${ }^{\mathrm{DHCF}}$, panels $(\mathbf{b}, \mathbf{d})$ against the two major combustion aerosols in $\mathrm{PM}_{1}$ and UFPs (biomass burning, panels (a,b), and fossil fuels UFPs, panels (c,d) Data time resolution is $2 \mathrm{~h}$. Number of points (N), Pearson correlation coefficient (multiple R and squared multiple R), Bonferroni probability $(\mathrm{P})$, confidence interval $(\mathrm{CI})$ on the regression line, and Spearman correlation coefficient $(\mathrm{S})$ are indicated.

Figure 3a provides a single schematic identifying the combustion aerosol sources associated to the larger oxidative responses. The red box $(y>0$ and $x<0$, Figure $3 a)$ represents the area grouping the larger oxidative responses. This area is positively associated to the fossil fuel UFPs. The blue box $(y<0$ and $x>0$ ) shows the lower oxidative responses, which is associated with the prevalent contribution of biomass burning. The remaining part of the schematic plot indicates mixed aerosol conditions ( $y>0$ and $x>0$, and/or $y<0$ and $x<0$ ). Panels $b-f$ of Figure 3 show how the aerosol metrics already described fall into this schematic. Comparing patterns in Figures $3 a$ and $3 b, c$, it can be seen that for both $\mathrm{PM}_{2.5}$ and $\mathrm{BC}$, lower (higher) mass concentration values occur for higher (lower) $\mathrm{OP}$ values and therefore for higher (lower) oxidative/inflammatory responses, i.e., red box (blue box). Considering the $f_{B C}$ (Figure $3 d$ ), in most cases, the larger $f_{B C}$ values ( $f B C>0.25$ ) occur in the red box $(x<0$ and $y>0)$. It should be noted that the larger the fossil fuel UFPs, the larger the fBC (Figure $2 \mathrm{~d}$ ), whilst there is no correlation with biomass burning (the relation is not statistically significant, $p=0.732$, Figure 21). Considering the total particle number concentration $\left(\mathrm{N}_{\text {tot }}\right.$, Figure $\left.3 \mathrm{a}, \mathrm{e}\right)$, it is seen that most (but not all) of the larger $\mathrm{N}_{\text {tot }}$ values are associated with lower oxidative responses (blue box, $x>0$ ), and only some large $\mathrm{N}_{\text {tot }}$ values ( $\mathrm{y}>0$, mixed conditions) are associated with large oxidative responses. The higher oxidative responses $\left(x<-0.5,0<y<1.5\right.$, red box, Figure 3a) mostly occur for lower $\mathrm{N}_{\text {tot }}$ values. The aerosol metric most correlated to the fossil fuel UFPs during our experiment is the $D_{\text {med }}$ 
(Figure 2), i.e., the median diameter of the surface-area size distribution. Most of the lower $\mathrm{D}_{\text {med }}$ values are in the red box (Figure 3).
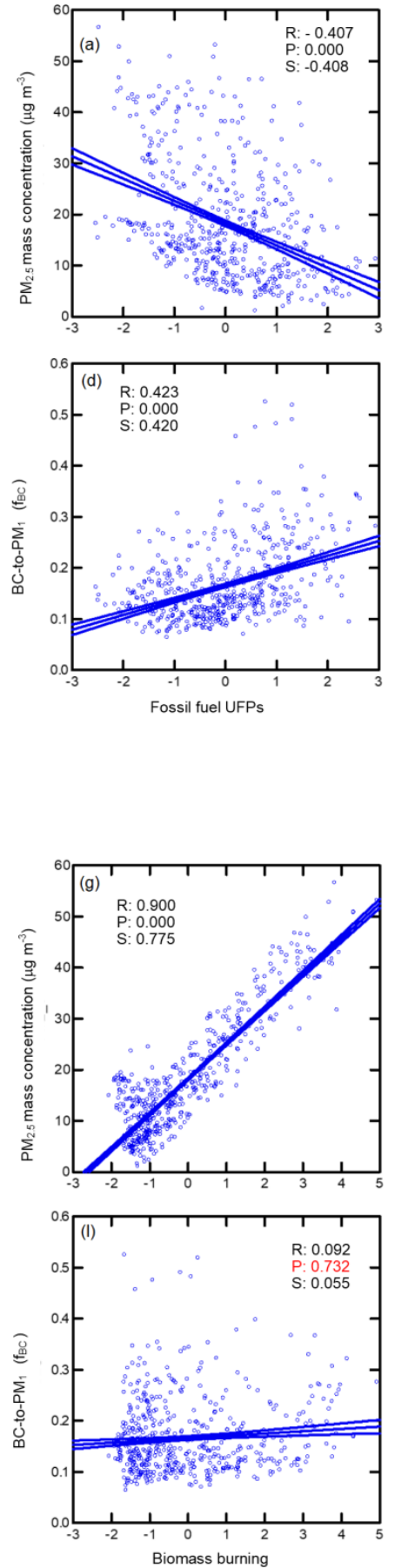

\section{FOSSIL FUEL UFPS}
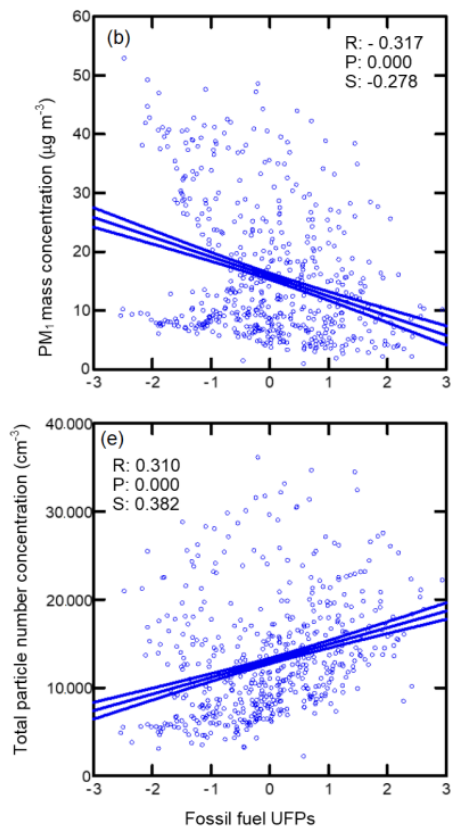

BIOMASS BURNING
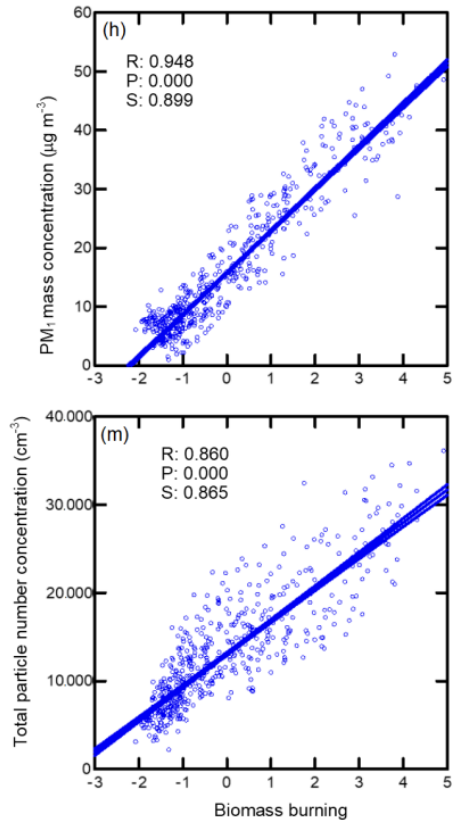
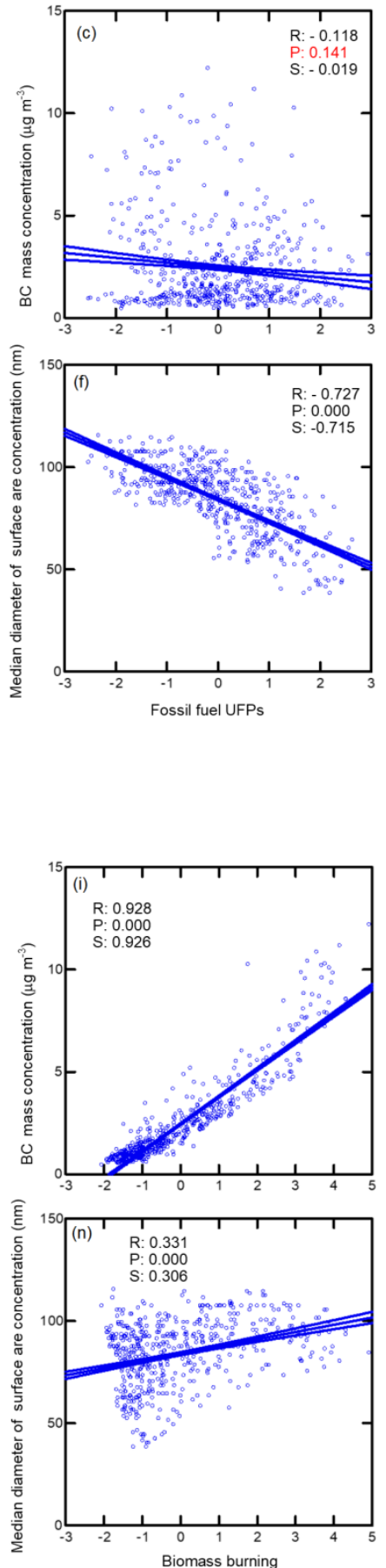

Figure 2. Regression lines between the two combustion derived aerosol types apportioned, fossil fuel UFPs (panels (a-f)) and biomass burning (panels ( $\mathbf{g}-\mathbf{n})$ ), and the aerosol metrics, $\mathrm{PM}_{2.5}, \mathrm{PM}_{1}$ mass concentration (panels $(\mathbf{a}, \mathbf{b}, \mathbf{g}, \mathbf{h}))$, BC mass concentration (panels $(\mathbf{c}, \mathbf{i})$ ), BC-to- $\mathrm{PM}_{1}$ mass fraction (panels $(\mathbf{d}, \mathbf{l})$ ), particle number concentration (panels $(\mathbf{e}, \mathbf{m})$ ), median particle diameter of the surface area size distribution (panels $(\mathbf{f}, \mathbf{n})$ ). Each panel shows the Pearson correlation coefficient(R), the Bonferroni probability $(\mathrm{P})$, and the Spearman correlation coefficient $(\mathrm{S})$. The number of cases is 529 ; the confidence interval of the regression lines is 0.5 ; data time resolution is $1 \mathrm{~h}$. 

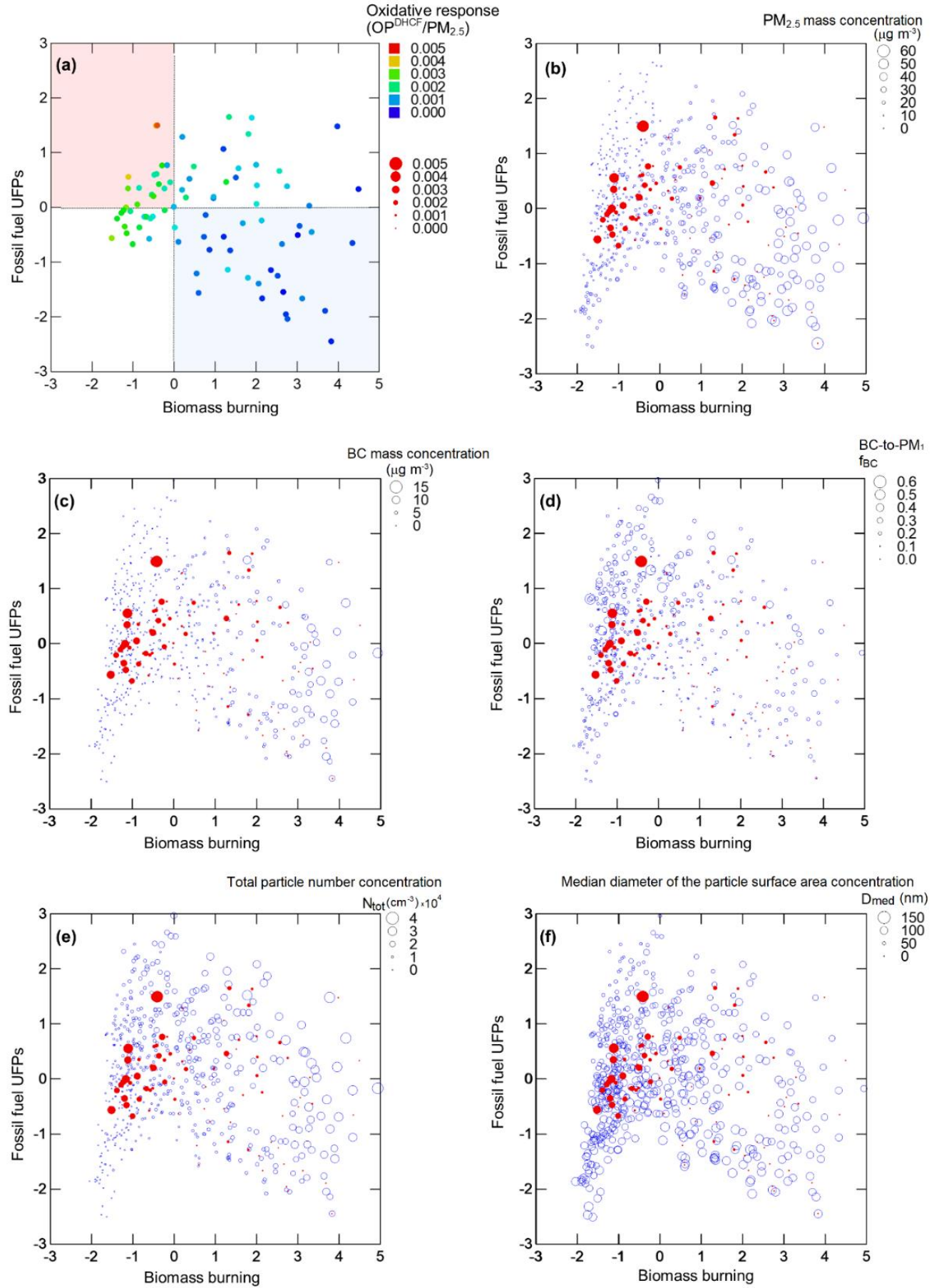

Figure 3. Relation between the two combustion derived aerosol types apportioned (fossil fuel UFPs and biomass burning), the oxidative responses $\left(\mathrm{OP}^{\mathrm{DHCF}} / \mathrm{PM}_{2.5}\right.$, panel (a)), and the aerosol metrics $\left(\mathrm{PM}_{2.5}\right.$ mass concentration, panel (b); BC mass concentration, panel (c); BC-to- $\mathrm{PM}_{1}$ mass fraction, panel (d); particle number concentration, panel (e); median particle diameter of the surface area size distribution, panel (f)). The oxidative responses in panels $\mathrm{b}$-f are indicated by red dots. Data time resolution is $2 \mathrm{~h}$ in panel (a), and $1 \mathrm{~h}$ in panels $(\mathbf{b}-\mathbf{f})$.

\section{Discussion}

In this section, we discuss previous results (Figures 1-3) in a broad context, how they can be interpreted from the perspective of previous findings obtained during the CARE experiments, and future studies. 


\subsection{UFPs Features Capturing Pro-Inflammatory and Oxidative Responses}

During the CARE experiment, the largest pro-inflammatory and oxidative responses were associated with a specific UFP "type" apportioned to fossil fuel combustion. Notably, only through the identification of this UFP type was it possible to "capture" the biological responses. The source apportionment of airborne UFPs is hence essential for human exposure studies. It provides an opportunity to take into account additional information like confounding factors, co-emitted pollutants, and environmental variables, which cannot be ruled out in the generation of the suspected health effects associated to UFPs. Worthy of note here is that the relations between the combustion aerosol and the oxidative responses (Figure 1) are monotonic, but not linear, suggesting that additional factors should be involved in the correlations observed.

The biological response proxy (the mass-normalised $\mathrm{OP}^{\mathrm{DHCF}}$ ) was associated to two specific aerosol metrics: the content of $\mathrm{BC}$ in $\mathrm{PM}_{1}\left(\mathrm{f}_{\mathrm{BC}}\right)$, and the particle surface-based median diameter $\mathrm{D}_{\text {med }}$ (Figures 1-3).It would be interesting to understand if $\mathrm{f}_{\mathrm{BC}}$ during the CARE experiment was a measure of the ultrafine $\mathrm{BC}(\mathrm{uBC})$. Based on the particle number size distribution and enrichment in BC of the fossil fuel UFPs (Figure 2d, Figure S1), we speculate that this is the case. Our results show that the larger $\mathrm{fBC}$ occur for the larger oxidative responses (Figure $3 \mathrm{~d}$ ). The association suggested between inflammation and ultrafine BC would be consistent with previous studies [30-32]. It is also consistent with Gualtieri et al.'s [48] results showing a Pearson correlation coefficient between CYP1B1 genes, representative of the xenobiotic responsive element and fBC of $0.96(p<0.001)$. Note, however, that there are large $\mathrm{fBC}$ values associated with low oxidative responses under "mixed" conditions $(x>3, y>0$, i.e., when the fossil fuel UFPs were mixed with the biomass burning aerosol, Figure 3$)$. This is, again, an argument for the importance of considering the source of UFPs and not relying on one single UFP metric only.

The results regarding the $D_{\text {med }}$ suggest an association between oxidative responses and the size of particles providing most of the surface area. In fact, the $D_{\text {med }}$ represents the value for which $50 \%$ of the total particle surface area concentration $\left(S_{\text {tot }}\right)$ in the given aerosol is associated with particles smaller than $\mathrm{D}_{\text {med }}$, and $50 \%$ of $S_{\text {tot }}$ is associated with particles larger than $D_{\text {med }}$. Notably, no association was found when using the median diameter calculated on the particle number size distribution (not shown here). We find larger oxidative responses when at least $50 \%$ of $S_{\text {tot }}$ is provided by the fossil fuel UFPs with diameters smaller than $70 \mathrm{~nm}$. These results are consistent with Gualtieri et al. [48], suggesting that $\mathrm{D}_{\text {med }}$ was a good indicator of the biological pro-inflammatory responses measured in-vitro: the Pearson correlation coefficient between CYP1B1 and $\mathrm{D}_{\text {med }}$ was $-0.74(p<0.001)$. Also in this case, as mentioned for $f_{B C}$, a few low values of $D_{\text {med }}$ can be associated to low oxidative responses (Figure 3 ). This occurs under mixed aerosol conditions $(x>0$ and $y>0$, i.e., presence of both fossil fuel UFPs and biomass burning, Figure 3f). It is again an argument for the importance of always considering UFP type and source. The relevance of the particle surface area for health effects is consistent with the literature $[8,9,19,20,22,34,46]$. Previous studies indicate how this is a measure of the particle's (surface) reactivity and capacity to carry adsorbed chemicals, possibly related to the promotion of cellular oxidative stress. We add to the literature on the importance of considering the size of particles offering the surface area. It may indicate the potential of particles, with high surface reactivity and adsorbed toxic molecules, to deposit and possibly translocate to different locations within the human body (increasing with decreasing the size [28]).

No association was found between the biological response proxy and the conventionally used metrics, $\mathrm{PM}_{2.5}$ and $\mathrm{BC}$ mass, and total particle number concentration (Figures 1-3). Results show that lower (higher) $\mathrm{PM}_{2.5}$ mass concentration values occur for higher (lower) OP values. This is in line with WHO conclusions that values of $\mathrm{PM}_{2.5}$ mass concentration even lower than $3-5 \mu \mathrm{g} \mathrm{m}^{-3}$ are not a safe health-relevant threshold [1]. We add to this that the same applies, at least in our experiment, for the $\mathrm{BC}$ mass concentration, for which no lower safe value is observed. We also add (not shown here) that the same pattern observed for $\mathrm{PM}_{2.5}$ and $\mathrm{BC}$ mass concentration is observed for the single-speciated mass concentrations here measured ( $\mathrm{PAH}, \mathrm{NH}_{4}{ }^{+}, \mathrm{NO}_{3}{ }^{-}, \mathrm{SO}_{4}{ }^{2-}$ ), as indicated by Gualtieri et al. [48]. 
The inverse relationship between the mass-normalised $\mathrm{OP}{ }^{\mathrm{DCFH}}$ and $\mathrm{PM}_{2.5}$ and $\mathrm{BC}$ mass concentration (Figures 1-3) is highly intriguing, and in our opinion, this result underlines once more the limitation of air quality mass-based metrics in catching and representing the complexity of biological responses. Notably, our findings on total particle number concentration $\left(\mathrm{N}_{\text {tot }}\right)$ show that even $\mathrm{N}_{\text {tot }}$ values lower than $10^{4} \mathrm{~cm}^{-3}$, which have been suggested as a possible "not to exceed" concentration limit [8], are not a safe threshold (at least during our experiment). This is consistent with previous findings [21,48]. Our findings could be related to the correlation observed between $\mathrm{N}_{\text {tot }}$ and biomass burning aerosol, which is definitely larger than that with fossil fuel UFPs (Figure 2e,m). Again, this is an argument for the importance of considering the UFP source rather than a single UFP metric when assessing possible health effects. The conventionally-used metrics, $\mathrm{PM}_{2.5}$ and $\mathrm{BC}$ mass, and total particle number concentration integrate all particles in a certain size range (e.g., less than $1000 \mathrm{~nm}$ ), regardless of the different aerosol types in that size range, their different toxicity, and the associated confounding factors. These "integrated" metrics are contemporaneously influenced by different aerosols, sources, and processes and hence disregard the different UFP types.

\subsection{Recommendations for Future Studies}

With the purpose to provide concise recommendations for the future, we summarise in Table 1 the three UFP features associated with the biological endpoints observed during the CARE experiment, i.e., the UFP "type" (source apportionment), the ultrafine-BC $\left(f_{B C}\right)$, and the size of the particles providing most of the surface reactive area (the $D_{\text {med }}$ ).

Table 1. UFP features associated with pro-inflammatory and oxidative responses during the CARE experiment.

\begin{tabular}{|c|c|c|c|}
\hline UFP Features & Biological Endpoint & Oxidative Potential & References \\
\hline $\begin{array}{l}\text { UFP “type" } \\
\text { (from source } \\
\text { apportionment } \\
\text { analysis) }\end{array}$ & $\begin{array}{l}\text { 8-Oxo-7,8-dihydroguanosine, } \\
\text { biomarker of oxidative damage } \\
\text { to RNA in the urine }\end{array}$ & $\begin{array}{c}\mathrm{OP}^{\mathrm{DHCF}} \text { of water-soluble } \mathrm{PM}_{2.5} \text { plus } \\
\text { suspended particle fraction passing } \\
\text { through } 0.45 \mu \mathrm{m} \text { filter, } \\
\text { which includes insoluble } \\
\text { non-agglomerated UFPs }\end{array}$ & $\begin{array}{c}\text { This work, } \\
{[50,51]}\end{array}$ \\
\hline BC-to-PM ${ }_{1}\left(f_{B C}\right)$ & $\begin{array}{l}\text { CYP1B1, representative of the } \\
\text { xenobiotic responsive element, } \\
\text { from bronchial epithelium cell } \\
\text { lines exposed at the ALI under } \\
\text { ambient air conditions }\end{array}$ & $\begin{array}{c}\mathrm{OP}^{\mathrm{DHCF}} \text { of water-soluble } \mathrm{PM}_{2.5} \text { plus } \\
\text { suspended particle fraction passing } \\
\text { through } 0.45 \mu \mathrm{m} \text { filter, } \\
\text { which includes insoluble } \\
\text { non-agglomerated UFPs }\end{array}$ & $\begin{array}{c}\text { This work, } \\
{[48,50]}\end{array}$ \\
\hline $\begin{array}{l}\text { Median diameter } \\
\text { of surface area } \\
\text { size distribution } \\
\left(D_{\text {med }}\right)\end{array}$ & $\begin{array}{l}\text { CYP1B1, representative of the } \\
\text { xenobiotic responsive element, } \\
\text { from bronchial epithelium cell } \\
\text { lines exposed at the ALI under } \\
\text { ambient air conditions }\end{array}$ & $\begin{array}{c}\mathrm{OP}^{\mathrm{DHCF}} \text { of water-soluble } \mathrm{PM}_{2.5} \text { plus } \\
\text { suspended particle fraction passing } \\
\text { through } 0.45 \mu \mathrm{m} \text { filter, } \\
\text { which includes insoluble } \\
\text { non-agglomerated UFPs }\end{array}$ & $\begin{array}{c}\text { This work } \\
{[48,50]}\end{array}$ \\
\hline
\end{tabular}

The final scenario provided by these three indicators is as follows. The highest pro-inflammatory and oxidative responses occurred when the aerosol was dominated by a UFP type apportioned to fossil fuel combustion. Its number size distribution was dominated by particles smaller than $20 \mathrm{~nm}$. It contained ultrafine BC-enriched particles (hence at least partly solid), accounting for on average more than $20 \%$ of the $\mathrm{PM}_{1}$ mass. More than $50 \%$ of the total reactive surface area available to toxic organic molecules (like PAH either co-emitted or already in the ambient air) was offered by particles smaller than $70 \mathrm{~nm}$. This UFP type had the potential to deposit in the lung and/or the olfactory bulb and/or translocate to other locations in the human body and promote harmful responses linked to DNA and/or RNA damages.

As a final remark, we note that caution should be taken when assessing health-relevant exposure to UFPs through "integrated" conventional metrics like the total particle number concentration and 
the $\mathrm{PM}_{2.5}$ and $\mathrm{BC}$ mass concentration. Translating high values of these "integrated" metrics into health effects may not necessarily be the case.

\subsection{Limitations of the Current Study}

We acknowledge a number of limitations which are relevant for the findings presented in this paper. Among these, there is the need to validate results at different sites affected by different sources, to test them through an epidemiological study, and to explore the role of confounding factors.

Furthermore, we are aware that the biological endpoints considered for our analysis are limited and other endpoints should be taken into consideration in the future. Accordingly, we do not assume that there is one or more UFP metrics relevant for any and all health effects. Our work here aimed at identifying metrics that can be considered as predictors only for the pro-inflammatory and oxidative responses observed during the CARE experiment. Although it is clearly limited, the approach relies on the oxidative stress paradigm, a well-recognized and accepted hypothesis for several air pollution-related health diseases. Our set of genes, although limited, is representative of the main biological pathways (oxidative response, xenobiotic response, and inflammation) involved in the onset of several human diseases. In the future, it is however desirable that a larger panel of genes is considered and with a higher number of samples, possibly representing in more detail the different PM properties areas here reported with association to the biological outcomes.

Finally, the possible causes explaining the correlations between the $\mathrm{OP}{ }^{\mathrm{DCHF}}$ and UFP features and the biological endpoints should be clarified. Here, we speculate that these could depend on both the assay (DCHF) and the data time resolution ( $2 \mathrm{~h}$ during the CARE experiment). Whilst other OP assays (like DTT) give a measure of the PM ability to generate ROS, the $\mathrm{OP}^{\mathrm{DCHF}}$ assay measures the ROS adsorbed upon the particle surface. This is an argument for the ability of the DCHF assay to "weigh" the highly reactive surface area assumed for the $\mathrm{uBC}$ particles, which were a large part of the fossil fuel UFPs. Further to that, whilst most of the OP studies rely on $24 \mathrm{~h}$ data, $\mathrm{OP}^{\mathrm{DCHF}}$ was measured during our study with a time resolution of $2 \mathrm{~h}$. This is an argument to speculate on its ability to detect the "short-lived" ROS species (half-life of minutes) [59], which should be more easily associated with the fossil fuel UFPs. Conversely, daily OP measurements (regardless of the assay used) should be rather able to detect the long-lived ROS fraction, which is stable for hours or days.

Supplementary Materials: The following are available online at http://www.mdpi.com/2073-4433/11/4/414/s1, Figure S1: Particle number size distribution and share of the major chemical components of the two combustion aerosols identified by a source apportionment analysis.

Author Contributions: Conceptualization, F.C., M.G., S.D.; methodology, F.C., M.G., S.C.; formal analysis, F.C., M.G.; investigation, F.C., M.G.; data curation, F.C., M.G., S.C.; writing-original draft preparation, F.C.; writing - review and editing, F.C., M.G., S.D., C.A., S.C. All authors have read and agreed to the published version of the manuscript.

Funding: The research performed under the CARE experiment received no external funding, other than the co-financing in kind (including materials used for experiments) from all the involved partners.

Acknowledgments: We acknowledge the work of all the participants in the CARE experiment, and specifically Gian Paolo Gobbi, Alfred Wiedensohler, Antonio Di Ianni, Kay Weinhold, Luca Di Liberto, Spartaco Ciampichetti, Honey Alas, Fulvio Amato, Michaela Aufderheide, Pasquale Avino, Stefania Argentini, Massimo Berico, Francesca Barnaba, Vera Bernardoni, Riccardo Biondi, Giulia Calzolai, Silvia Canepari, Giampietro Casasanta, Luisella Ciancarella, Alessandro Conidi, Eugenia Cordelli, Maria Cristina Facchini, Andrea Facci, Daniele Frasca, Stefania Gilardoni, Teresa La Torretta, Franco Lucarelli, Antonella Malaguti, Maurizio Manigrasso, Niklas Mohle, Mauro Montagnoli, Silvia Nava, Francesca Pacchierotti, Elio Padoan, Cinzia Perrino, Igor Petenko, Xavier Querol, Giuseppe Raschella, Giulia Simonetti, Milena Stracquadanio, Giovanna Tranfo, Stefano Ubertini, Gianluigi Valli, Sara Valentini, Roberta Vecchi, Francesca Volpi, and Gabriele Zanini. Special thanks to Roma Capitale for its sponsorhip and in particular to Giuseppina Montanari, Giuseppe Lanzi, Stefano Cicerani, Silvano Simoni, Vincenzo Cimaglia, Massimo Rascioni, and Daniele Rocchi.

Conflicts of Interest: The authors declare no conflict of interest. 


\section{References}

1. World Health Organization. Ambient Air Pollution: A Global Assessment of Exposure and Burden of Disease; World Health Organization: Geneva, Switzerland, 2016; pp. 1-121, ISBN 9789241511353.

2. Cohen, A.J.; Brauer, M.; Burnett, R.; Anderson, H.R.; Frostad, J.; Estep, K.; Balakrishnan, K.; Brunekreef, B.; Dandona, L.; Dandona, R. Estimates and 25-year trends of the global burden of disease attributable to ambient air pollution: An analysis of data from the Global Burden of Diseases Study 2015. Lancet 2017, 389, 1907-1918. [CrossRef]

3. GBD 2016 Risk Factors Collaborators. Global, regional, and national comparative risk assessment of 84 behavioral, environmental and occupational, and metabolic risks or clusters of risks, 1990-2016: A systematic analysis for the Global Burden of Disease Study 2016. Lancet 2017, 390, 1345-1422. [CrossRef]

4. Lelieveld, J.; Evans, J.S.; Fnais, M.; Giannadaki, D.; Pozzer, A. The contribution of outdoor air pollution sources to premature mortality on a global scale. Nature 2015, 525, 367-371. [CrossRef] [PubMed]

5. European Commission. Directive 2008/50/EC of the European Parliament and of the Council of 21 May 2008 on ambient air quality and cleaner air for Europe. Off. J. Eur. Union 2008, 152, 1-44.

6. World Health Organization. Occupational and Environmental Health Team. (2006). WHO Air Quality Guidelines for Particulate Matter, Ozone, Nitrogen Dioxide and Sulfur Dioxide: Global Update 2005: Summary of Risk Assessment. Available online: https://apps.who.int/iris/handle/10665/69477 (accessed on 19 April 2020).

7. Papadogeorgou, G.; Kioumourtzoglou, M.A.; Braun, D.; Zanobetti, A. Low Levels of Air Pollution and Health: Effect Estimates, Methodological Challenges, and Future Directions. Curr.Environ. Health Rep. 2019, 6, 105-115. [CrossRef] [PubMed]

8. Baldauf, R.W.; Devlin, R.B.; Gehr, P.; Giannelli, R.; Hassett Sipple, B.; Jung, H.; Martini, G.; McDonald, J.; Sacks, J.D.; Walker, K. Ultrafine Particle Metrics and Research Considerations: Review of the 2015 UFP Workshop. Int. J. Environ. Res. Public Health 2016, 13, 1054. [CrossRef]

9. Hennig, F.; Quass, U.; Hellack, B.; Küpper, M.; Kuhlbusch, T.A.J.; Stafoggia, M.; Hoffmann, B. Ultrafine and fine particle number and surface area concentrations and daily cause-specific mortality in the Ruhr Area, Germany, 2009-2014. Environ. Health Perspect. 2018, 15, 126. [CrossRef]

10. Costabile, F.; Birmili, W.; Klose, S.; Tuch, T.; Wehner, B.; Wiedensohler, A.; Franck, U.; König, K.; Sonntag, A. Spatiotemporal variability and principal components of the particle number size distribution in an urban atmosphere. Atmos. Chem. Phys. 2009, 9, 3163-3195. [CrossRef]

11. Brines, M.; Dall'Osto, M.; Beddows, D.C.S.; Harrison, R.M.; Gómez-Moreno, F.; Núñez, L.; Artínano, B.; Costabile, F.; Gobbi, G.P.; Salimi, F.; et al. Traffic and nucleation events as main sources of ultrafine particles in high-insolation developed world cities. Atmos. Chem. Phys. 2015, 15, 5929-5945. [CrossRef]

12. Minguillón, M.C.; Perron, N.; Querol, X.; Szidat, S.; Fahrni, S.M.; Alastuey, A.; Jimenez, J.L.; Mohr, C.; Ortega, A.M.; Day, D.A.; et al. Fossil versus contemporary sources of fine elemental and organic carbonaceous particulate matter during the DAURE campaign in Northeast Spain. Atmos. Chem. Phys. 2011,11, 12067-12084. [CrossRef]

13. Visser, S.; Slowik, J.G.; Furger, M.; Zotter, P.; Bukowiecki, N.; Dressler, R.; Flechsig, U.; Appel, K.; Green, D.C.; Tremper, A.H.; et al. Kerb and urban increment of highly time-resolved trace elements in PM10, PM2.5 and PM1.0 winter aerosol in London during ClearfLo 2012. Atmos. Chem. Phys. 2015, 15, 2367-2386. [CrossRef]

14. Kelly, F.J.; Fussell, J.C. Size, source and chemical composition as determinants of toxicity attributable to ambient particulate matter. Atmos. Environ. 2012, 60, 504-526. [CrossRef]

15. Verma, V.; Fang, T.; Xu, L.; Peltier, R.E.; Russell, A.G.; Ng, N.L.; Weber, R.J. Organic aerosols associated with the generation of Reactive Oxygen Species (ROS) by water-soluble $\mathrm{PM}_{2.5}$. Environ. Sci. Technol. 2015, 49, 4646-4656. [CrossRef] [PubMed]

16. Lowther, S.D.; Jones, K.C.; Wang, X.; Whyatt, J.D.; Wild, O.; Booker, D. Particulate matter measurement indoors: A review of metrics, sensors, needs, and applications. Environ. Sci. Technol. 2019, 53, 11644-11656. [CrossRef]

17. García-Hernández, C.; Ferrero, A.; Estarlich, M.; Ballester, F. Exposure to ultrafine particles in children until 18 years of age: A systematic review. Indoor Air 2020, 30, 7-23. [CrossRef]

18. Heal, M.R.; Kumar, P.; Harrison, R.M. Particles, air quality, policy and health. Chem. Soc. Rev. 2012, 41, 6606. [CrossRef] 
19. Noël, A.; Truchon, G.; Cloutier, Y.; Charbonneau, M.; Maghni, K.; Tardif, R. Mass or total surface area with aerosol size distribution as exposure metrics for inflammatory, cytotoxic and oxidative lung responses in rats exposed to titanium dioxide nanoparticles. Toxicol. Ind. Health 2016. [CrossRef]

20. Ruckerl, R.; Schneider, A.; Hampel, R.; Breitner, S.; Cyrys, J.; Kraus, U.; Gu, J.; Soentgen, J.; Koenig, W.; Peters, A. Association of Novel Metrics of Particulate Matter with Vascular Markers of Inflammation and Coagulation in Susceptible Populations-Results from a Panel Study. Environ. Res. 2016, 150, 337-347. [CrossRef]

21. Xue, J.; Hu, S.; Quiros, D.; Ayala, A.; Jung, H.S. How do particle number, surface area, and mass correlate with toxicity of diesel particle emissions as measured in chemical and cellular assays? Chemosphere 2019, 229, 559-569. [CrossRef]

22. Hussain, S.; Boland, S.; Baeza-Squiban, A.; Hamel, R.; Thomassen, L.C.; Martens, J.A.; Billon-Galland, M.A.; Fleury-Feith, J.; Moisan, F.; Pairon, J.C.; et al. Oxidative stress and proinflammatory effects of carbon black and titanium dioxide nanoparticles: Role of particle surface area and internalized amount. Toxicology 2009, 260, 142-149. [CrossRef]

23. Sager, T.M.; Castranova, V. Surface area of particle administered versus mass in determining the pulmonary toxicity of ultrafine and fine carbon black: Comparison to ultrafine titanium dioxide. Part. Fibre Toxicol. 2009, 6, 15. [CrossRef] [PubMed]

24. International Agency for Research on Cancer (IARC), World Health Organization. IARC Monographs 2016, No 109. On the Evaluation of Carcinogenic Risks to Humans. Available online: https://publications.iarc.fr/538 (accessed on 19 April 2020).

25. Chen, H.; Kwong, J.C.; Copes, R.; Tu, K.; Villeneuve, P.J.; van Donkelaar, A.; Hystad, P.; Martin, R.V.; Murray, B.J.; Jessiman, B.; et al. Living near major roads and the incidence of dementia, Parkinson's disease, and multiple sclerosis: A population-based cohort study. Lancet 2017, 389, 718-726. [CrossRef]

26. Calderón-Garcidueñas, L.; Reynoso-Robles, R.; González-Maciel, A. Combustion and friction-derived nanoparticles and industrial-sourced nanoparticles: The culprit of Alzheimer and Parkinson's diseases. Environ. Res. 2019, 176, 108574. [CrossRef] [PubMed]

27. Chew, S.; Kolosowska, N.; Saveleva, L.; Malm, T.; Kanninen, K.M. Impairment of mitochondrial function by particulate matter: Implications for the brain. Neurochem. Int. 2020, 135, 104694. [CrossRef]

28. Oberdörster, G.; Sharp, Z.; Atudorei, V.; Elder, A.; Gelein, R.; Kreyling, W.; Cox, C. Translocation of inhaled ultrafine particles to the brain. Inhal. Toxicol. 2004, 16, 437-445. [CrossRef]

29. Stone, V.; Miller, M.R.; Clift, M.J.D.; Elder, A.; Mills, N.L.; Møller, P.; Schins, R.P.F.; Vogel, U.; Kreyling, W.G.; Alstrup Jensen, K.; et al. Nanomaterials Versus Ambient Ultrafine Particles: An Opportunity to Exchange Toxicology Knowledge. Environ. Health Perspect. 2017, 125, 106002. [CrossRef]

30. Bové, H.; Bongaerts, E.; Slenders, E.; Bijnens, E.M.; Saenen, N.D.; Gyselaers, W.; Van Eyken, P.; Plusquin, M.; Roeffaers, M.B.J.; Ameloot, M.; et al. Ambient black carbon particles reach the fetal side of human placenta. Nat. Commun. 2019, 10, 3866. [CrossRef]

31. Heusinkveld, H.J.; Wahle, T.; Campbell, A.; Westerink, R.H.; Tran, L.; Johnston, H.; Stone, V.; Cassee, F.R.; Schins, R.P. Neurodegenerative and neurological disorders by small inhaled particles. Neurotoxicology 2016, 56, 94-106. [CrossRef]

32. Shang, Y.; Liu, M.; Wang, T.; Wang, L.; He, H.; Zhong, Y.; Qian, G.; An, J.; Zhu, T.; Qiu, X.; et al. Modifications of autophagy influenced the Alzheimer-like changes in SH-SY5Y cells promoted by ultrafine black carbon. Environ. Pollut. 2019, 246, 763-771. [CrossRef]

33. Health Effects Institute. Understanding the Health Effects of Ambient Ultrafine Particles; HEI Perspectives 3; Health Effects Institute: Boston, MA, USA, 2013.

34. Ohlwein, S.; Kappeler, R.; Joss, M.K.; Künzli, N.; Hoffmann, B. Health effects of ultrafine particles: A systematic literature review update of epidemiological evidence. Int.J. Public Health 2019, 64, 547-559. [CrossRef]

35. Peel, J.L.; Tolbert, P.E.; Klein, M.; Metzger, K.B.; Flanders, W.D.; Todd, K.; Mulholland, J.A.; Ryan, P.B.; Frumkin, H. Ambient air pollution and respiratory emergency department visits. Epidemiology 2005, 16, 164-174. [CrossRef] [PubMed]

36. Leitte, A.M.; Schlink, U.; Herbarth, O.; Wiedensohler, A.; Pan, X.C.; Hu, M.; Richter, M.; Wehner, B.; Tuch, T.; $\mathrm{Wu}, \mathrm{Z}$; et al. Size-segregated particle number concentrations and respiratory emergency room visits in Beijing, China. Environ. Health Perspect. 2011, 119, 508-513. [CrossRef] [PubMed] 
37. Samoli, E.; Andersen, Z.J.; Katsouyanni, K.; Hennig, F.; Kuhlbusch, T.A.; Bellander, T.; Cattani, G.; Cyrys, J.; Forastiere, F.; Jacquemin, B.; et al. UF\&HEALTH Study group. Exposure to ultrafine particles and respiratory hospitalisations in five European cities. Eur. Respir. J. 2016, 48, 674-682. [CrossRef]

38. Tobías, A.; Rivas, I.; Reche, C.; Alastuey, A.; Rodríguez, S.; Fernández-Camacho, R.; Sánchez de la Campa, A.M.; de la Rosa, J.; Sunyer, J.; Querol, X. Short-term effects of ultrafine particles on daily mortality by primary vehicle exhaust versus secondary origin in three Spanish cities. Environ. Int. 2018, 111, 144-151. [CrossRef]

39. Lanzinger, S.; Schneider, A.; Breitner, S.; Stafoggia, M.; Erzen, I.; Dostal, M.; Pastorkova, A.; Bastian, S.; Cyrys, J.; Zscheppang, A.; et al. UFIREG study group Associations between ultrafine and fine particles and mortality in five central European cities-Results from the UFIREG study. Environ. Int. 2016, 88, 44-52. [CrossRef] [PubMed]

40. Stafoggia, M.; Schneider, A.; Cyrys, J.; Samoli, E.; Andersen, Z.J.; Bedada, G.B.; Bellander, T.; Cattani, G.; Eleftheriadis, K.; Faustini, A.; et al. Association between Short-term Exposure to Ultrafine Particles and Mortality in Eight European Urban Areas. Epidemiology 2017, 28, 172-180. [CrossRef] [PubMed]

41. Ostro, B.; Hu, J.; Goldberg, D.; Reynolds, P.; Hertz, A.; Bernstein, L.; Kleeman, M.J. Associations of Mortality with Long-Term Exposures to Fine and Ultrafine Particles, Species and Sources: Results from the California Teachers Study Cohort. Environ. Health Perspect. 2015, 123, 549-556. [CrossRef]

42. Li, Y.; Lane, K.J.; Corlin, L.; Patton, A.P.; Durant, J.L.; Thanikachalam, M.; Woodin, M.; Wang, M.; Brugge, D. Association of Long-Term Near-Highway Exposure to Ultrafine Particles with Cardiovascular Diseases, Diabetes and Hypertension. Int. J. Environ. Res. Public Health 2017, 14, 461. [CrossRef]

43. Weichenthal, S.; Bai, L.; Hatzopoulou, M.; Van Ryswyk, K.; Kwong, J.C.; Jerrett, M.; van Donkelaar, A.; Martin, R.V.; Burnett, R.T.; Lu, H.; et al. Long-term exposure to ambient ultrafine particles and respiratory disease incidence in in Toronto, Canada: A cohort study. Environ. Health 2017, 16, 64. [CrossRef]

44. Downward, G.S.; van Nunen, E.J.H.M.; Kerckhoffs, J.; Vineis, P.; Brunekreef, B.; Boer, J.M.A.; Messier, K.P.; Roy, A.; Verschuren, W.M.M.; van der Schouw, Y.T.; et al. Long-Term Exposure to Ultrafine Particles and Incidence of Cardiovascular and Cerebrovascular Disease in a Prospective Study of a Dutch Cohort. Environ. Health Perspect. 2018, 126, 127007. [CrossRef]

45. Bai, L.; Weichenthal, S.; Kwong, J.C.; Burnett, R.T.; Hatzopoulou, M.; Jerrett, M.; van Donkelaar, A.; Martin, R.V.; Van Ryswyk, K.; Lu, H.; et al. Associations of Long-Term Exposure to Ultrafine Particles and Nitrogen Dioxide With Increased Incidence of Congestive Heart Failure and Acute Myocardial Infarction. Am. J. Epidemiol. 2019, 188, 151-159. [CrossRef] [PubMed]

46. Chen, K.; Schneider, A.; Cyrys, J.; Wolf, K.; Meisinger, C.; Heier, M.; von Scheidt, W.; Kuch, B.; Pitz, M.; Peters, A.; et al. Hourly Exposure to Ultrafine Particle Metrics and the Onset of Myocardial Infarction in Augsburg, Germany. Environ. Health Perspect. 2020, 128, 1. [CrossRef] [PubMed]

47. Costabile, F.; Alas, H.; Aufderheide, M.; Avino, P.; Amato, F.; Argentini, S.; Barnaba, F.; Berico, M.; Bernardoni, V.; Biondi, R.; et al. First Results of the "Carbonaceous Aerosol in Rome and Environs (CARE)" Experiment: Beyond Current Standards for PM10. Atmosphere 2017, 8, 249. [CrossRef]

48. Gualtieri, M.; Grollino, M.G.; Consales, C.; Costabile, F.; Manigrasso, M.; Avino, P.; Aufderheide, M.; Cordelli, E.; Di Liberto, L.; Petralia, E.; et al. Is it the time to study air pollution effects under environmental conditions? A case study to support the shift of in vitro toxicology from the bench to the field. Chemosphere 2018, 207, 552-564. [CrossRef] [PubMed]

49. Di Ianni, A.; Costabile, F.; Barnaba, F.; Di Liberto, L.; Weinhold, K.; Wiedensohler, A.; Struckmeier, C.; Drewnick, F.; Gobbi, G. Black Carbon Aerosol in Rome (Italy): Inference of a Long-Term (2001-2017) Record and Related Trends from AERONET Sun-Photometry Data. Atmosphere 2018, 9, 81. [CrossRef]

50. Costabile, F.; Gualtieri, M.; Canepari, S.; Tranfo, G.; Consales, C.; Grollino, M.G.; Paci, E.; Petralia, E.; Pigini, D.; Simonetti, G. Evidence of association between aerosol properties and in-vitro cellular oxidative response to PM1, oxidative potential of PM2.5, a biomarker of RNA oxidation, and its dependency on the combustion aerosol. Atmos. Environ. 2019, 213, 444-455. [CrossRef]

51. Tranfo, G.; Paci, E.; Carrieri, M.; Marchetti, E.; Sisto, R.; Gherardi, M.; Costabile, F.; Bauleo, L.; Ancona, C.; Pigini, D. Levels of urinary biomarkers of oxidatively generated damage to DNA and RNA in different groups of workers compared to general population volunteers. Int. J. Environ. Res. Public Health 2019, 16, 2995. [CrossRef] 
52. Alas, H.D.C.; Weinhold, K.; Costabile, F.; Di Ianni, A.; Müller, T.; Pfeifer, S.; Di Liberto, L.; Turner, J.R.; Wiedensohler, A. Methodology for high-quality mobile measurement with focus on black carbon and particle mass concentrations. Atmos. Meas. Tech. 2019, 12, 4697-4712. [CrossRef]

53. Valentini, S.; Barnaba, F.; Bernardoni, V.; Calzolai, G.; Costabile, F.; Di Liberto, L.; Forello, A.C.; Gobbi, G.P.; Gualtieri, M.; Lucarelli, F.; et al. Classifying aerosol particles through the combination of optical and physical-chemical properties: Results from a wintertime campaign in Rome (Italy). Atmos. Res. 2020, 235, 104799. [CrossRef]

54. Manigrasso, M.; Costabile, F.; Di Liberto, L.; Gobbi, G.P.; Gualtieri, M.; Zanini, G.; Avino, P. Size resolved Aerosol respiratory doses in a Mediterranean urban area: From PM10 to ultrafine particles. Environ. Intern. 2020, accepted.

55. Costabile, F.; Gilardoni, S.; Barnaba, F.; Di Ianni, A.; Di Liberto, L.; Dionisi, D.; Manigrasso, M.; Paglione, M.; Poluzzi, V.; Rinaldi, M.; et al. Characteristics of brown carbon $\mathrm{n}$ the urban Po Valley atmosphere. Atmos. Chem. Phys. 2017, 17, 114. [CrossRef]

56. Simonetti, G.; Frasca, D.; Marcoccia, M.; Farao, C.; Canepari, S. Multi-elemental analysis of particulate matter samples collected by a particle-into-liquid sampler. Atmos. Pollut. Res. 2018, 9, 747-754. [CrossRef]

57. Simonetti, G.; Conte, E.; Perrino, C.; Canepari, S. Oxidative potential of size-segregated PM in an urban and an industrial area of Italy. Atmos. Environ. 2018, 187, 292-300. [CrossRef]

58. Fiorello, A.; Amato, F.; Bernardoni, V.; Calzolai, G.; Canepari, S.; Costabile, F.; Di Liberto, L.; Gualtieri, M.; Lucarelli, F.; Nava, S.; et al. Gaining knowledge on source contribution to aerosol optical absorption properties and organics by receptor modelling. Atmos. Environ. 2020, submitted.

59. Fuller, S.; Wragg, F.; Nutter, J.; Kalberer, M. Comparison of on-line and off-line methods to quantify reactive oxygen species (ROS) in atmospheric aerosols. Atmos. Environ. 2014, 92, 97103. [CrossRef]

(C) 2020 by the authors. Licensee MDPI, Basel, Switzerland. This article is an open access article distributed under the terms and conditions of the Creative Commons Attribution (CC BY) license (http://creativecommons.org/licenses/by/4.0/). 